\title{
A MÚSICA NA LUPA DA PSICOLOGIA FACE À PANDEMIA: COVID19!
}

\author{
Claro, C \\ Aluna do 3ªno de Psicologia da Universidade Autónoma de Lisboa \\ cat.claro@hotmail.com \\ Lapa Esteves, M. \\ Docente da Universidade Autónoma de Lisboa (UAL). Portugal. \\ mlesteves@autonoma.pt
}

Recepción Artículo: 13 marzo 2020

Admisión Evaluación: 17 marzo 2020

Informe Evaluador 1: 1 abril 2020

Informe Evaluador 2: 7 abril enero 2020

Aprobación Publicación: 20 abril 2020

\section{RESUMO}

0 mundo desafinou ao som de um vírus chamado Covid19, e se já era importante a música na nossa vida, mais significativa se tornou, de extrema importância nesta quarentena obrigatória para milhões de habitantes do planeta terra. A música surge como estratégia para uma boa saúde mental para aliviar o confronto com a redução de liberdade que se viram abruptamente a ter que aceitar. Assim surge este estudo exploratório não só para analisarmos uma música na sua construção, planeamento, escolhas de tónicas (a nota que "manda"), como em que frequência vibra, exemplo, a frequência $329 \mathrm{~Hz}$. Esta frequência está associada a melhorias na respiração, no grounding (base/conhecimentos dos factos) e melhora o estado de fluxo (flow state: estado mental de operação na qual a pessoa está totalmente imersa no que está a fazer, caracterizado por um sentimento total de envolvimento e sucesso no processo de atividade). Assim procuraremos perscrutar como funciona a música, bem como colocar a música na lupa da Psicologia ao serviço da comunidade face a esta pandemia!

Palavras-chave: música; pandemia; Covid19; comunidade; saúde pública; psicologia

\section{ABSTRACT}

The music in the magnifying glass of psychology in the face of the pandemic: Covid19! The world went out of tune with the sound of a virus called Covid19, and if music was already important in our lives, it became more and more important in this mandatory quarantine for millions of habitants of planet Earth. Music emerges as a strategy for good mental health to alleviate the confrontation with the reduction of freedom that they abruptly found themselves having to accept. Thus, this exploratory study arises not only to analyze a song in its construction, planning, choice of tonic (the note that "sends"), but in what frequency vibrates, for example, the frequency $329 \mathrm{~Hz}$. This frequency is associated with improvements in breathing, in grounding (basis / knowledge of the facts) and improves the state of flow (flow state: mental state of operation in which the person is totally immersed in what he is doing, characterized by a total feeling involvement and success in the activity process). 


\section{A MÚSICA NA LUPA DA PSICOLOGIA FACE À PANDEMIA: COVID19!}

In this way we will try to investigate how music works, as well as placing music in the lens of Psychology at the service of the community in the face of this pandemic!

Keywords: music; pandemic; covid19; community; public health; psychology

\section{INTRODUÇÃo}

0 mundo desafinou ao som de um vírus chamado Covid19, e se já era importante a música na nossa vida, mais significativa se tornou, de extrema importância nesta quarentena obrigatória para milhões de habitantes do planeta terra. A música surge como estratégia para uma boa saúde mental para aliviar o confronto com a redução de liberdade que se viram abruptamente a ter que aceitar. Assim surge este estudo exploratório não só para analisarmos uma música na sua construção, planeamento, escolhas de tónicas (a nota que "manda"), como em que frequência vibra, exemplo, a frequência de $329 \mathrm{~Hz}$. Esta frequência está associada a melhorias na respiração, no grounding (base/conhecimentos dos factos) e melhora o estado de fluxo (flow state: estado mental de operação na qual a pessoa está totalmente imersa no que está a fazer, caracterizado por um sentimento total de envolvimento e sucesso no processo de atividade). Assim procuraremos perscrutar como funciona a música, bem como colocar a música na lupa da Psicologia ao serviço da comunidade face a esta pandemia!

\section{DESENVOLVIMENTO}

Segundo Longfellow (1866) "music is the universal language of mankind", sendo utilizada como meio para a expressão humana e associada a diversos contextos sociais e religiosos (Oliveira \& Gomes, 2014).

Desde a pré-história que a música tem um impacto muito grande na vida do ser humano, sendo utilizada como um dos principais meios de comunicação, no entanto, esta função não deixou de existir sendo observada em sessões de musicoterapia com clientes com patologias inibidoras da comunicação, (Oliveira \& Gomes, 2014) como é por exemplo o caso de crianças com autismo (Bieleninik et al., 2017; Miller-Jones, 2017).

No entanto, como é que a música comunica? Segundo Charles Sanders Pierce (citado por Fernandes, 2006) a comunicação na música é alcançada por meio da ação dos signos, e é através destes que é possível haver uma transmissão de informação.

A música funciona como um instrumento de diálogo não-verbal, funcionando de uma forma inata e pode desencadear profundos processos de transformação pessoal (Weigsding \& Barbosa, 2014), possuindo um poder que ultrapassa os níveis de escuta e oralidade, podendo influenciar o público ouvinte-recetor sendo utilizada por vezes pelos media como uma ferramenta persuasiva capaz de alterar o funcionamento psicológico do indivíduo (Fernandes, 2006).

A importância da música na vida do ser humano tem sido alvo de interesse pelas áreas da Filosofia como também pelas Ciências Naturais, (Santos, 2012) não só como fenómeno artístico, mas também como capaz de produzir efeitos catárticos influenciando a parte fisiológica e mesmo produzir a cura (Oliveira \& Gomes, 2014). No entanto, qual é a música mais indicada para produzir a catarse? Existe algum tipo de música mais indicado do que outro? Estas foram algumas das respostas que os filósofos gregos tentaram encontrar, como por exemplo, Platão e Aristóteles, diferindo em termos de opinião acerca de qual a música mais válida. Aristóteles possuía uma visão holística, acreditando que todos os instrumentos e todos os tipos de músicas são válidos desde que fossem utilizados no contexto indicado (Oliveira \& Gomes, 2014).

As discussões filosóficas sobre os efeitos da música no Homem continuaram, no entanto, apenas em meados do século XIX é que a relação entre música e psicologia foi estabelecida com a publicação de um tratado denominado Sobre as sensações dos tons como base fisiológica para a Teoria da Música em 1863 por Helmholtz relacionando a música com a perceção sensorial (Santos, 2012; Avila, 2009).

Segundo Santos (2012), hoje, a investigação em psicologia da música e musicoterapia é vasta e, podemos dividir em quatro grandes temas:

1. A nível da cognição a investigação procura estabelecer a diferença entre a experiência musical de músicos e não-músicos; 
2. A investigação de determinadas características da prática de uma atividade musical e 0 efeito nos comportamentos dos músicos e resultado dos produtos musicais atingidos;

3. Procura-se perceber de que forma a música nos influencia a nível do desenvolvimento cognitivo, percetivo, (Falcão, 2016) e psicossocial;

4. Estudar as diferenças e semelhanças na cultura musical, procurando aspetos universais.

Diversos estudos têm sido realizados no sentido de compreender quais os efeitos da música, não só da prática como também da audição, na depressão, stress e ansiedade. Tem sido sugerido que ouvir música produz benefícios à saúde e que tem efeitos redutores do stress, sendo uma ferramenta económica, não invasiva e com aceitação elevada (Thoma et al., 2013). 0 stress resulta da experiência do individuo ao receber determinado estímulo e este assume que não tem os recursos para responder e manter o equilíbrio (Thoma et al., 2013). Ao ouvir música estamos a iniciar uma quantidade enorme de processos cognitivos no cérebro, assim, é passível de assumir que esta atividade pode influenciar os processos cognitivos relativos ao stress e como consequência influenciar a nossa resposta fisiológica (Thoma et al., 2013). Segundo Lepping et al. (2016) a audição musical é utilizada para a regulação emocional, pois, a música que dá prazer ao indivíduo ativando assim o sistema dopaminérgico do cérebro.

A regulação emocional é uma capacidade crítica para a manter a saúde mental e o bem-estar. "Music is a powerful inducer of emotion, and people often report using music as a tool for regulating their emotional state. (...) Music is also used for mood change in the population generally, and as a coping strategy specifically in depression" (Lepping et al., 2016).

\section{INVESTIGAÇÂO}

\section{Metodologia}

No sentido de compreender a influência da música e a sua importância na regulação emocional da população portuguesa na pandemia foi realizado um questionário através da plataforma Google que foi divulgado através de contactos de email, da aplicação WhatsApp e das redes sociais como o Facebook. 0 questionário tinha a duração de 3 minutos e consistia em perguntas diretas de escolha múltipla, perguntas abertas e perguntas com a utilização da escala de Likert. Através deste questionário tentamos obter não só a visão dos adultos sobre a música e a sua importância no quotidiano face à pandemia, como também a visão das crianças e adolescentes, assim sendo, estabelecemos como limite inferior de idade os 6 anos, ou seja, o começo da idade escolar.

\section{Participantes}

Os participantes são oriundos de contatos pessoais, extrapolados para contatos dos contatos, amigos, conhecidos, familiares. Uma amostra que se quis aleatória, heterogénea, quer de participantes feminino como masculino, de diferentes idades, a partir dos 6 anos equivalente ao 1ํano escolar. A nossa amostra é constituída por 122 participantes. Dos quais 70,5\% da amostra é do género feminino e 29,5\% do género masculino.

Gráfico 1: "Género"

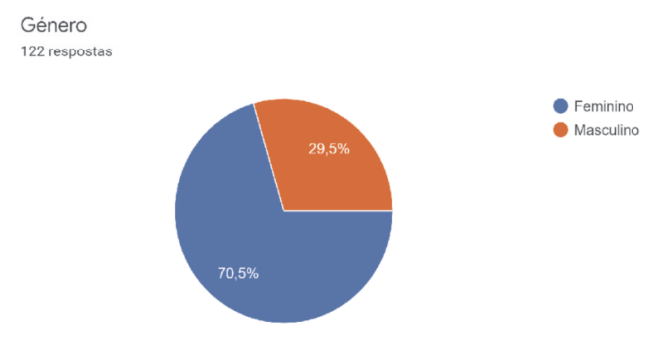




\section{A MÚSICA NA LUPA DA PSICOLOGIA FACE À PANDEMIA: COVID19!}

$73 \%$ dos participantes tinham mais de 23 anos, 18,9\% tinham entre 19 a 23 anos, 1,6\% entre os 15 e 18 anos, $4,9 \%$ entre os 11 e 14 e 1,6\% entre 6 e 10 anos.

Gráfico 2: "Idade"

Idade

122 respostas

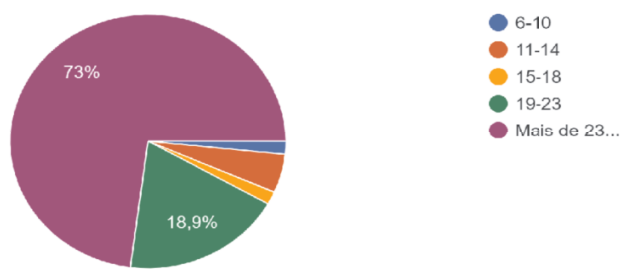

A nível da situação profissional 46,7\% da amostra é trabalhador, 18\% trabalhador-estudante e 35,2\% é estudante.

\section{Gráfico 3: "Situação Profissional"}

Situação Profissional

122 respostas

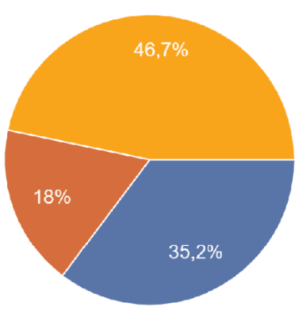

A nível do estado civil 58,2\% da amostra é solteiro, 26,2\% casado, 5,7\% divorciado e 9,8\% encontra-se em união de fato.

\section{Gráfico 4: "Estado Civil"}

Estado Civil

122 respostas
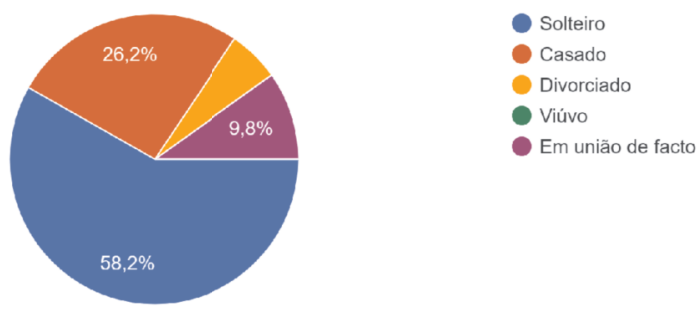

Em união de facto 
Questionamos os participantes relativamente ao número de dias em que se encontravam em isolamento e obtemos uma grande diversidade de respostas, sendo que 12 pessoas da amostra ainda não tinha estado em isolamento, 42 pessoas da amostra estão em casa entre 1 a 15 dias, e de 16 dias a 35 as restantes 68 pessoas.

\section{Resultados}

Relativamente à audição da música durante a quarenta 95,1\% afirma que tem ouvido música e apenas 4,9\% afirma que não e 14,8\% respondeu que a audição da música não ajuda a lidar com a pandemia e 85,2\% afirma que ouvir música é uma forma de lidar com a pandemia.

\section{Gráfico 5: "Tem ouvido música durante a quarentena?"}
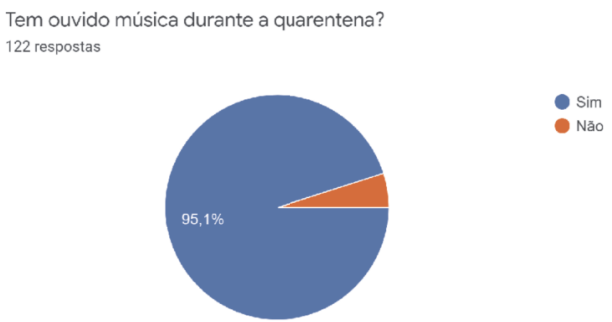

Gráfico 6: "Ouvir música ajuda-o a lidar com a pandemia?"

Ouvir música ajuda-o a lidar com a pandemia?

122 respostas

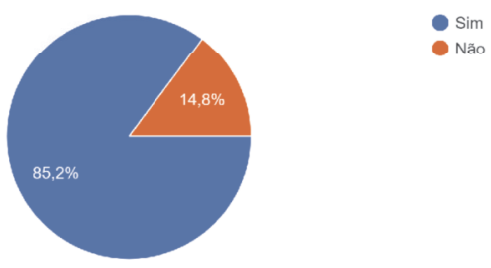

No entanto, de que forma pode a música ajudar a lidar com a pandemia? Na análise de conteúdo, os principais fatores enunciados pelos participantes afirmam que a música funciona como um escape e que permite esquecer e distrair dos problemas do mundo real, acalmando e sendo uma ferramenta importante para lidar com a ansiedade e 0 stress trazendo sentimentos de bem-estar, motivação, felicidade, esperança; funcionando assim como uma ferramenta de regulação emocional.

Pretendemos também perceber se os participantes sentiam um aumento da frequência com que ouve música, sendo que, como apresentado anteriormente, muitos encontram-se em casa, aferimos que 44,3\% refere que houve sim um aumento da audição musical e 55,7\% afirma que não. 


\section{A MÚSICA NA LUPA DA PSICOLOGIA FACE À PANDEMIA: COVID19!}

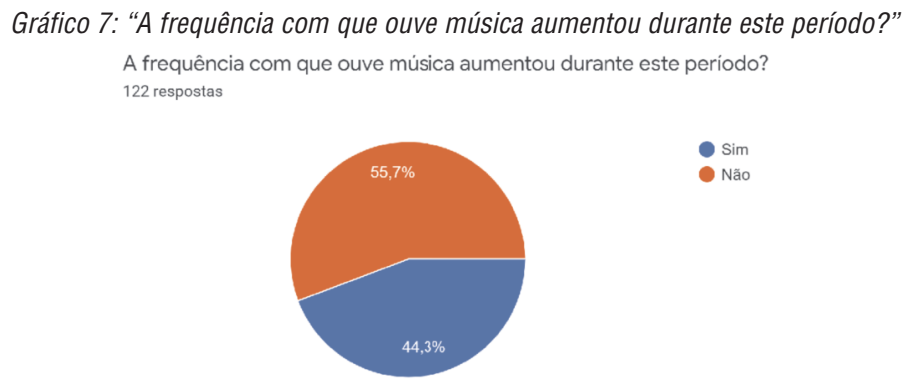

A quantidade de horas que os participantes dedicam diariamente é importante para perceber a importância da música no seu quotidiano, nos resultados obtidos 45,9\% dedicam mais de 2 horas diárias à audição musical, 16,4\% dedicam 2 horas, 23\% ouvem uma hora diária por dia e 14,8\% dos 122 participantes dedicam menos de uma hora diária.

Gráfico 8: "Durante quanto tempo costuma ouvir música ao longo do dia?"

Durante quanto tempo costuma ouvir música ao longo do dia?

122 respostas

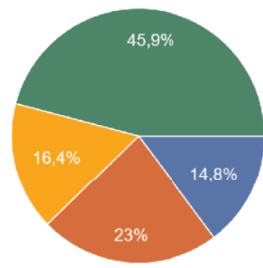

1 hora
2 horas
mais de 2 horas por dia

Estando já estabelecido que $\mathbf{8 5 , 2 \%}$ dos participantes afirmam que a música ajuda a lidar com a pandemia através da regulação emocional, então, pretendemos perceber quais os principais sentimentos que a música transmitia a estes participantes dentro dos diversos sentimentos ou emoções identificados os sentimentos que foram referidos com mais frequência foram: alegria, felicidade, paz, calma, tranquilidade e relaxamento. No entanto, alguns participantes afirmaram que se conseguia sentir todos os sentimentos e emoções através da música dependendo da música que ouviam. De seguida, pretendemos perceber em que medida os participantes sentiam que a música acalma e pedimos que identificasse numa escala de likert de 1 a 5 , sendo que 1 seria nada e 5 sempre. 
Gráfico 9: "Em que medida a música acalma?"

Em que medida sente que a música acalma?

115 respostas

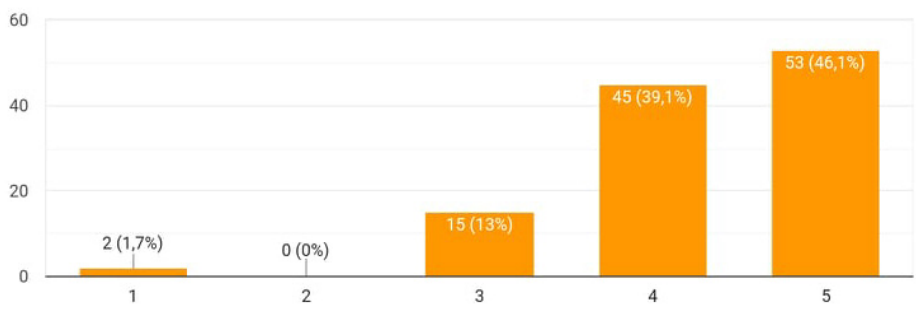

Numa altura em que nos vemos obrigados a entrar em quarentena foram diversas as iniciativas a surgir no sentido de combater 0 isolamento social, sensibilizar para a importância de ficar em casa e ao mesmo tempo sensibilizar para 0 trabalho precário dos artistas (Correia, 2020; MadreMedia, 2020; Morais, 2020).

Assim, procuramos perceber que impacto provocaram estas iniciativas:

\section{Gráfico 10: Impacto da musica na vida enquanto esteve em quarentena}

Que impacto teve na sua vida, durante a quarentena, as iniciativas (ex. festival fique em casa) dos nossos músicos/cantores/artistas?

115 respostas

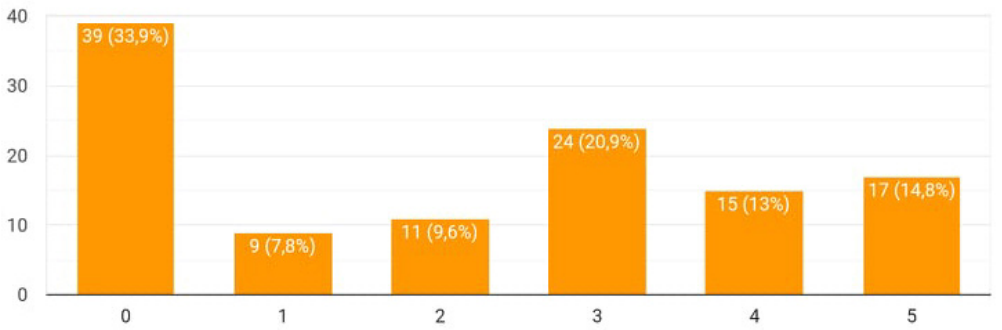

Para além da escuta, a prática musical tem muitos benefícios ao nível do sentimento de bem-estar (Pires, Galinha \& Herédia, 2017), e, assim questionamos os participantes se tinham pratica instrumental e apenas $28,7 \%$ da amostra, ou seja 35 dos 122 participantes, toca algum instrumento musical em que a média de horas de prática encontra-se entre 0 horas a 2 horas.

A nível do aumento da atividade $37,1 \%$ dos participantes afirma que não houve aumento da frequência com que pratica, $17,1 \%$ afirma que talvez tenha sentido um aumento da atividade e $45,7 \%$ dos participantes afirma que tem praticado mais nestes dias de quarentena. 


\section{A MÚSICA NA LUPA DA PSICOLOGIA FACE À PANDEMIA: COVID19!}

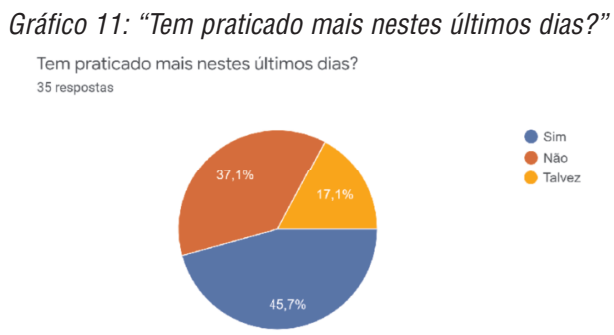

A nível dos motivos que potenciaram esse aumento da atividade $46,2 \%$ da amostra refere que é devido a ter mais tempo, 15,4\% para manter a motivação, 15,4\% afirma que quando toca não pensa na pandemia e $23,1 \%$ afirma ser outro motivo como por exemplo para aperfeiçoar a técnica ou todas as opções anteriores.

\section{Gráfico 12: "Se sim qual o principal motivo que levou ao aumento da sua atividade musical?"

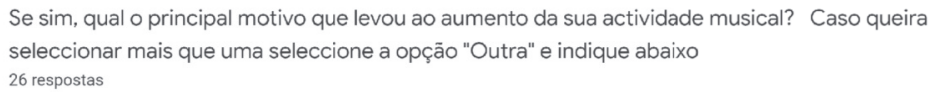

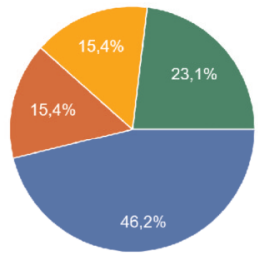

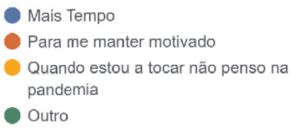

\section{Analisando uma canção em pormenor "Não me deixes partir" dos HMB.}

A capacidade de a música influenciar o estado emocional do indivíduo deve-se ao facto de ela produzir reações fisiológicas cuja magnitude parece depender do seu conteúdo emocional. Assim sendo, a perceção musical depende de muitas variáveis, e envolve muitas áreas encefálicas, sendo a música a arte com uma grande representação neuropsicológica (Weigsding \& Barbosa, 2014). Ouvir música é uma experiência motora para além de auditiva e emocional, existe a tendência de 0 indivíduo acompanhar a melodia e o ritmo da música, involuntariamente, mesmo quando a música existe apenas no nosso mundo interior (Sacks, 2008).

A música é definida pelo ritmo, pela melodia, pela harmonia, pelo timbre (amplitude), pela dinâmica, pela forma, (Simões, 2012) pela altura (frequência) e ainda pela intensidade.

A música é composta de sons e, 0 som resulta de vibrações nas partículas de ar que variam na sua amplitude e frequência (Weigsding \& Barbosa, 2014). As notas musicais resultam de uma classificação subjetiva de frequências sonoras ao longo do nosso espectro de audição, (Rodrigues, 2009) sendo que o nosso ouvido humano consegue captar frequências entre os 20 e $20000 \mathrm{~Hz}$ (Henrique, 2014).

Ao longo dos séculos várias têm sido as tentativas e propostas de associação entre as cores e as notas musicais, ou seja, entre o mundo visível e o invisível (Macedo, 2009; Campos, 2014). A frequência $329 \mathrm{~Hz}$, que corresponde a nota $\mathrm{Mi}$ (E) que é a tónica da música apresentada e à volta da qual a música se desenvolve, é associada à cor violeta (Macedo, 2009) que a nível da psicologia é uma cor associada ao sentimento de esperança e a tranquilidade (Lacy, 2000). A dominante da escala de Mi (E) é Lá (A), que se encontra entre os $432 \mathrm{~Hz}$ ou 440 $\mathrm{Hz}$, é denominada como a frequência milagre, uma frequência de som puro que produz um efeito tranquilizante a quem a ouve e traz diversos benefícios a nível da saúde física (Nahas \& IMD, 2017). 
NĀO ME DEIXES PARTIR - HMB

CIFRA

Tom: E

[Intro] E7M D7 E7M D7

C\#m7 $\quad$ F\#7 $\quad$ A7M $\quad$ G\#7

Fecho os olhos e imagino que não vivo mais, não vivo mais

$$
\begin{array}{lll}
\mathbf{C} \# \mathbf{m} 7 & \mathbf{B m} 7
\end{array}
$$

E que importa se louco sou

A7M F\#7

E somos desiguais, dizem os demais

\title{
F\#m11 G\#m7 A7M G\#m7 F\#m11
}

Fui criança com pressa de crescer
F\#m11 G7(13)
F\#7

Mas hoje a vida à força faz-me perceber

\section{F\#m11 G\#m7 A7M $\quad$ G\#m7 F\#m11}

Que tudo a seu tempo tem o seu valor
F\#m11 G\#7
$\mathbf{A} / \mathbf{B}$

Tudo a seu tempo tem o seu valor

$\begin{array}{cc}\text { E9 } & \text { Bm7 } \\ \text { Não, não me } & \text { deixes partir } \\ \text { A7M(9) } & \text { F\#m7 }\end{array}$

Sem entender o que temos aqui

E9 $\quad$ Bm7

Não, não me deixes partir
A7M
E/G\# F\#m7

Sem entender o que temos nós dois

C\#m7 $\quad$ F\#7

A7M

Quem sabe, de repente, faz-me um sinal

G\#7

Apenas um sinal

$\begin{array}{lll}\text { C\#m7 } & \text { Bm7 } & \text { A7M }\end{array}$

Um gesto simples, não complicado nem ousado

F\#7

Apenas um sinal

\author{
F\#m11 G\#m7 A7M G\#m7 F\#m11 \\ Fui criança com pressa de crescer \\ F\#m11 G7(13) F\#7 \\ Mas hoje a vida à força faz-me perceber \\ F\#m11 G\#m7 A7M G\#m7 F\#m11 \\ Que tudo a seu tempo tem o seu valor \\ F\#m11 G\#7 A/B \\ Tudo a seu tempo tem o seu valor
}




\title{
A MÚSICA NA LUPA DA PSICOLOGIA FACE À PANDEMIA: COVID19!
}

\author{
E9 $\quad$ Bm7 \\ Não, não me deixes partir \\ A7M(9) $\quad$ F\#m7 \\ Sem entender o que temos aqui \\ E9 $\quad$ Bm7 \\ Não, não me deixes partir \\ A7M E/G\# F\#m7
}

Sem entender o que temos nós dois

( A/B E5 $>$ B/C\# Bb9/C A/B E5 Am7 Bm7 A/B )

\author{
E9 $\quad$ Bm7 \\ Não, não me deixes partir \\ A7M(9) $\quad$ F\#m7 \\ Sem entender o que temos aqui \\ E9 $\quad$ Bm7 \\ Não, não me deixes partir \\ A7M $\quad$ E/G\# $\quad$ F\#m7
}

Sem entender o que temos nós dois

[Final] E7M D7

Assim estabelecidas as notas que "mandam" na música, podemos passar à letra e às mensagens destas. Com mais ou menos consciência do grupo quando escreveu a letra de quão profunda é a mensagem e de quanto poderá ela transmitir a todos os seus fãs, foi com toda a certeza escrita com muito amor e dedicação, com um sentimento positivo de transmitir uma mensagem positiva incitando ao ouvinte uma reflexão e autoanálise.

Analisando quanto às notas dominantes e à mensagem podemos verificar que é uma música de esperança, logo no início começa com uma espécie de pedido ao ouvinte para imaginar-se a não viver mais, e como é que seria, o que é que importa ser louco e ser diferente dos outros?

Passa-nos também a mensagem que as coisas tem tempo e lugar, e que se não aconteceu ainda irá acontecer a seu tempo, e se aconteceu isso levou a um amadurecimento e à pessoa que se é no momento presente. Entenda-se "o não me deixes partir", da pessoa para a vida, no sentido, "não me deixes morrer" sem que tenha percebido o seu lugar no mundo e o seu propósito de viver, e pede uma mensagem ao mundo (a cada um que canta) para compreender o que deve fazer (ou seja, ter esperança e confiança que se vai compreender e compreender 0 seu propósito).

Poder-se-á ver num ângulo amoroso e quem a canta, poder cantar na ode ao seu par amoroso, "e não deixes que isto acabe sem que perceber a mesma", aos olhos da psicologia e da psicanálise o desejo de saber 0 impacto que o próprio tem no outro.

Quer seja a tomada de consciência, intuitivamente; quer seja a interpretação individual, toda a música inspira esperança e augura esperança.

\section{CONCLUSÃO}

A música possui inúmeros benefícios no ser humano, quer seja, a nível do seu desenvolvimento cognitivo, como também a nível do sentimento subjetivo de bem-estar.

A música, é para além de uma arte, uma forma de comunicar, como tal, está repleta de mensagens que têm influência no nosso pensar, no nosso comportamento e nas várias esferas da nossa vida. Assim, é importante perceber, para além do nosso gosto musical, que influencia possui a música, que emoções nos transmite e quais 
as suas mensagens descodificadas pelo público. Nem sempre a mensagem descodificada corresponde à mensagem pensada pelo seu emissor, no entanto, esse problema é geral a toda a comunicação.

A música pode ser utilizada das mais diversas formas, no entanto, tal como os nossos participantes enunciaram, a música pode ser um escape da realidade, um promotor de sentimentos de presença, tranquilidade e esperança, e, como tal, a sua importância nesta época de incerteza não pode ser ignorada.

\section{INTERVENÇ̃̃O PSICOLÓGICA}

Quis a Psicologia dar o seu contributo para a compreensão da utilização da música face a este quadro de crise mundial, de uma pandemia vinda de surpresa; por ser igualmente inesperada, desconhecida e de muito difícil de controlar à nossa comunidade científica, aos nossos governantes e à população geral; e gerar tanta ansiedade, desconforto, stress, angústia. Sintomas que de forma alguma poderiam passar despercebidos aos Psicólogos.

À Psicologia cabe não só tratar dos transtornos psico-emocionais e mentais, como compreender o que pode ser usado como uma ferramenta para aliviar todo o tipo de sintomatologia e proporcionar bem-estar físico, psicológico e mental neste período de quarentena.

Este estudo exploratório, do tipo descritivo, tem por objetivo ser um de mais e futuros estudos, para além de trazer à luz tantas outras parcerias que podem e devem ser usadas, como neste caso, a música.

Movimentos musicais surgiram com toda a espontaneidade, generosidade; de uma forma altruística por amadores e por músicos profissionais que se disponibilizaram logo no primeiro instante. A todos os que nos proporcionaram tantos e bons momentos musicais, o nosso GIGANTE BEM-HAJAM!

Verificou-se assim, que a MÚSICA pode e deve ser usada em situações de crise, de pandemia, em situações de quarentena; sempre foi, será e hoje, é com toda a certeza, de uma extrema utilidade para se manter a lucidez e 0 bem estar psicológico/mental, em qualquer idade.

\section{REFERÊNCIAS BIBLIOGRÁFICAS}

Avila, D. C. (2009). Das (Im)Possibilidades de uma Psicologia Musical. TransFormações em Psicologia (Online), 2(2), 81-99. Recuperado em 23 de março de 2020, de http://pepsic.bvsalud.org/scielo.php?script=sci_arttext\&pid=S2176-106X2009000200005\&lng=pt\&tlng=pt

Bieleninik, Ł., Geretsegger, M., Mössler, K., Assmus, J., Thompson, G., Gattino, G., Elefant, C., Gottfried, T., Igliozzi, R., Muratori, F., Suvini, F., Kim, J., Crawford, M. J., Odell-Miller, H., Oldfield, A., Casey, Ó., Finnemann, J., Carpente, J., Park, A.-L., ... Gold, C. (2017). Effects of improvisational music therapy vs enhanced standard care on symptom severity among children with autism spectrum disorder: The TIME-A randomized clinical trial. JAMA: Journal of the American Medical Association, 318(6), 525-535. https://bon.ual.pt:2238/10.1001/jama.2017.9478

Campos, C. H. B. (2014). Sinestesias do som e da imagem, da música e de cores ao VJ. In Intercom-Sociedade Brasileira de Estudos Interdisciplinares da Comunicação. XXXVII Congresso Brasileiro de Ciências da Comunicação. São Paulo.

Correia, G. (2020, Março 16). Chegou o fim-de-semana, continua o Festival Eu Fico em Casa: saiba onde ver os concertos no Instagram. Observador. Retirado de: https://observador.pt/2020/03/16/festival-eu-fico-emcasa-os-maiores-nomes-da-musica-portuguesa-vao-dar-nos-musica-no-instagram/

Fernandes, M. C. (2006). Comunicação, Semiótica e Música: relações e reflexões. Intercom Sudoeste 2006Simpósio de Ciências da Comunicação na Região Sudoeste.

Henrique, L. L. (2014). Sistema Auditivo. In Henrique, L.L (5를) Acústica Musical (pp. 810-858). Lisboa, Portugal: Fundação Calouste Gulbenkian.

Lacy, M. L. (2000). Poder das cores no equilíbrio dos ambientes. Editora Pensamento. 


\section{A MÚSICA NA LUPA DA PSICOLOGIA FACE À PANDEMIA: COVID19!}

Lepping, R. J., Atchley, R. A., Chrysikou, E., Martin, L. E., Clair, A. A., Ingram, R. E., Simmons, W. K., \& Savage, C. R. (2016). Neural processing of emotional musical and nonmusical stimuli in depression. PLoS ONE, 11(6).

MadreMedia, L. (2020, Março 25) Mais de 80 músicos e atores atuam a partir de sexta-feira no HomeStage Festival. SAPO 24. Retirado de: https://24.sapo.pt/atualidade/artigos/mais-de-80-musicos-e-atores-atuama-partir-de-sexta-feira-no-homestage-festival

Miller-Jones, A. M. (2017). The Effect of Music Therapy upon Language Acquisition for Children on the Autism Spectrum Aged 3-8 Years [ProQuest LLC]. In ProQuest LLC.

Morais, N. (2020, Março 16). Artistas unem-se em iniciativa inédita em Portugal para sensibilizar a população a ficar em casa. Rádio Televisão Portuguesa. Retirado de: https://www.rtp.pt/antena1/os-dias-da-radio/festival-eu-fico-em-casa_11170

Nahas, A. R., \& IMD, D. E. (2017). A Cabala Quântica. Clube de Autores (managed).

Oliveira, C. C. \& Gomes, A. (Ed.) (2014). Breve História da Musicoterapia, Suas Conceptualizações e Práticas: Actas do XII Congresso da Sociedade Portuguesa de Ciências da Educação 2014. Vila Real: Universidade Trás-os-Montes e Alto Douro.

Pires, Anabela \& Galinha, Iolanda \& Herédia, Afonso. (2017). Estudo Experimental: Impacto de Grupos de Canto no Bem-estar Subjetivo de Seniores. Psychology, Community \& Health. 6. 186-200. 10.5964/pch.v6i1.159.

Sacks, 0. (2008) Musicofilia - Histórias sobre a Música e o Cérebro. Lisboa: Relógio d’Água Editores.

Simões, A. R. C. (2012). As Emoções ao compasso da música: um olhar sobre a influência da música na resposta emocional (Doctoral dissertation).

Teixeira dos Santos, R. (2012). Psicologia da Música: Aportes Teóricos e Metodológicos por mais de um sécuIo. Música em Perspectiva, 5(1). doi:http://dx.doi.org/10.5380/mp.v5i1.30143

Thoma MV, la Marca R, Brönnimann R, Finkel L, Ehlert U, Nater UM. The effect of music on the human stress response. PLOS ONE. 2013;8(8). http://b-on.ual.pt:2061/login.aspx?direct=true\&db=psyh\&AN=201329803-001\&lang=pt-pt\&site=ehost-live. Accessed March 23, 2020.

Weigsding, J. A., \& Barbosa, C. P. (2014). A influência da música no comportamento humano. Arquivos do MUDI, Maringá, 18(2), 47-62. 